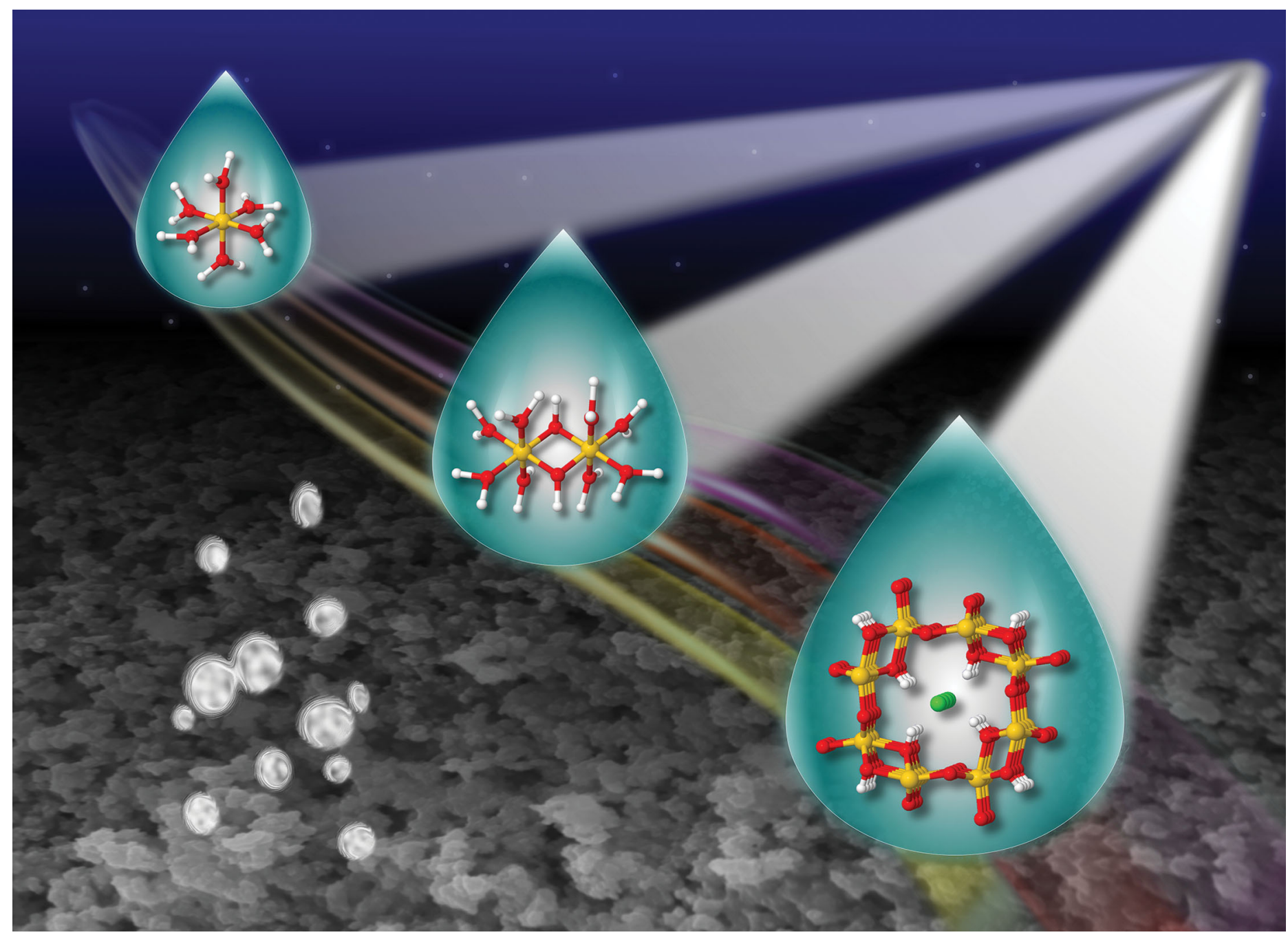

Showcasing research from the Groups of Dr Bernd Winter at Fritz-Haber-Institut der Max-Planck-Gesellschaft,

Dr Ralph Kraehnert at Technische Universität Berlin, and Dr Franziska Emmerling at the BAM Federal Institute for Materials Research and Testing, Berlin, Germany.

Detection of the electronic structure of iron-(III)-oxo oligomers forming in aqueous solutions

The nature of the small iron-oxo oligomers in iron-(III) aqueous solutions has a determining effect on the chemical processes that govern the formation of nanoparticles in the aqueous phase. Using liquid-jet photoelectron spectroscopy the electronic structures of the occurring iron-oxo oligomeric seeds are measured. Seeds are produced by adding $\mathrm{NaOH}$ to $0.75 \mathrm{M}$ $\mathrm{FeCl}_{3}$ aqueous solution. At small enough $\mathrm{NaOH}$ concentrations, corresponding to $[\mathrm{OH}] /[\mathrm{Fe}]=0.2-0.25$ ratios, the seeds can be stabilized for several hours without engaging in further aggregation.

\section{As featured in:}

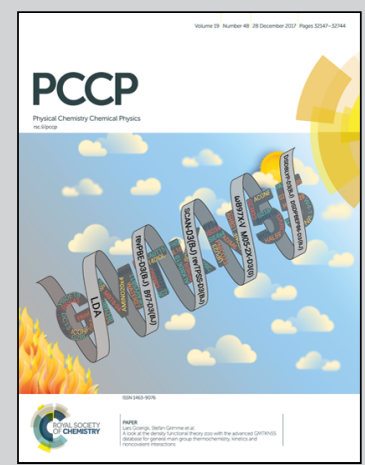

See Ralph Kraehnert,

Franziska Emmerling,

Bernd Winter et al., Phys. Chem.

Chem. Phys., 2017, 19, 32226.

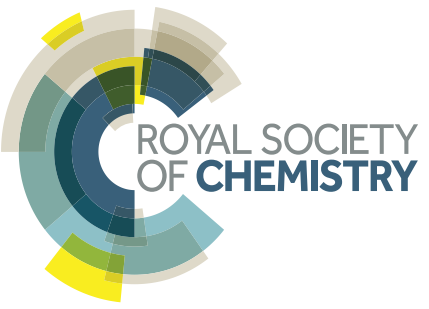


Check for updates

Cite this: Phys. Chem. Chem. Phys., 2017, 19, 32226

Received 11th October 2017, Accepted 2nd November 2017

DOI: $10.1039 / c 7 c p 06945 f$

rsc.li/pccp

\title{
Detection of the electronic structure of iron-(III)-oxo oligomers forming in aqueous solutions $\dagger$
}

\author{
Robert Seidel, $\ddagger^{\mathrm{ab}}$ Katrin Kraffert, (D) $\ddagger^{\mathrm{c}}$ Anke Kabelitz, $\ddagger^{\mathrm{bd}}$ Marvin N. Pohl, \\ Ralph Kraehnert, ${ }^{* \mathrm{C}}$ Franziska Emmerling (D) ${ }^{* d}$ and Bernd Winter (D) *e
}

\begin{abstract}
The nature of the small iron-oxo oligomers in iron-(III) aqueous solutions has a determining effect on the chemical processes that govern the formation of nanoparticles in aqueous phase. Here we report on a liquid-jet photoelectron-spectroscopy experiment for the investigation of the electronic structure of the occurring iron-oxo oligomers in $\mathrm{FeCl}_{3}$ aqueous solutions. The only iron species in the as-prepared $0.75 \mathrm{M}$ solution are $\mathrm{Fe}^{3+}$ monomers. Addition of $\mathrm{NaOH}$ initiates $\mathrm{Fe}^{3+}$ hydrolysis which is followed by the formation of iron-oxo oligomers. At small enough $\mathrm{NaOH}$ concentrations, corresponding to approximately $[\mathrm{OH}] /[\mathrm{Fe}]=0.2-0.25$ ratio, the iron oligomers can be stabilized for several hours without engaging in further aggregation. Here, we apply a combination of non-resonant as well as iron $2 p$ and oxygen 1 s resonant photoelectron spectroscopy from a liquid microjet to detect the electronic structure of the occurring species. Specifically, the oxygen 1s partial electron yield X-ray absorption (PEY-XA) spectra are found to exhibit a peak well below the onset of liquid water and $\mathrm{OH}^{-}$(aq) absorption. The iron $2 \mathrm{p}$ absorption gives rise to signal centered between the main absorption bands typical for aqueous $\mathrm{Fe}^{3+}$. Absorption bands in both PEY-XA spectra are found to correlate with an enhanced photoelectron peak near $20 \mathrm{eV}$ binding energy, which demonstrates the sensitivity of resonant photoelectron (RPE) spectroscopy to mixing between iron and ligand orbitals. These various signals from the iron-oxo oligomers exhibit maximum intensity at $[\mathrm{OH}] /[\mathrm{Fe}]=0.25$ ratio. For the same ratio, we observe changes in the $\mathrm{pH}$ as well as in complementary Raman spectra, which can be assigned to the transition from monomeric to oligomeric species. At approximately $[\mathrm{OH}] /[\mathrm{Fe}]=0.3$ we begin to observe particles larger than $1 \mathrm{~nm}$ in radius, detected by small-angle $\mathrm{X}$-ray scattering.
\end{abstract}

\section{Introduction}

Iron-(III)-based oxides, oxohydroxides, and hydroxides (short iron-(III) oxides) are among the most important environmental metal compounds, playing a major role in biological processes and technology. In nature, these metal oxides assist in controlling the $\mathrm{pH}$ of surface-, ground-, and sea water, and also influence microbiological activity or sorption of nutrients and trace elements. ${ }^{1-6}$ Technological applications are diverse, and include

\footnotetext{
${ }^{a}$ Helmholtz-Zentrum Berlin für Materialien und Energie, Institute for Material Development, Albert-Einstein-Strasse 15, D-12489 Berlin, Germany

${ }^{b}$ Humboldt-Universität zu Berlin, Department of Chemistry, Brook-Taylor-Str. 2, D-12489 Berlin, Germany

${ }^{c}$ Technische Universität Berlin, Department of Chemistry, Strasse des 17. Juni 124, D-10623 Berlin, Germany. E-mail: ralph.kraehnert@tu-berlin.de

${ }^{d}$ BAM Federal Institute for Materials Research and Testing, Richard-Willstätter Strasse 11, D-12489 Berlin, Germany. E-mail: franziska.emmerling@bam.de

${ }^{e}$ Fritz-Haber-Institut der Max-Planck-Gesellschaft, Faradayweg 4-6, D-14195 Berlin, Germany.E-mail:winter@fhi-berlin.mpg.de

$\dagger$ Electronic supplementary information (ESI) available. See DOI: 10.1039/ c7cp06945f

\$ These authors contributed equally.
}

utilization in medicine, ${ }^{7}$ magnetic storage, ${ }^{8,9}$ sensing, ${ }^{10-12}$ as well as catalysis. ${ }^{13,14}$ Given their wide impact iron oxides have been intensively studied experimentally and theoretically, with focus on both the transformation of atomic $\mathrm{Fe}^{3+}$ into $\mathrm{Fe}_{n} \mathrm{O}_{x} \mathrm{H}_{y}$ oligomers (here referred to as seeds) in aqueous solution, and on the characterization of the solid-phase aggregates and crystals (referred to as particles) which form upon subsequent agglomeration. At very low $\mathrm{pH}$ the dominant iron complex in $\mathrm{FeCl}_{3}$ aqueous solution is $\left(\mathrm{Fe}\left[\mathrm{H}_{2} \mathrm{O}\right]_{5} \mathrm{OH}\right)^{2+}$, followed by $\left(\mathrm{Fe}\left[\mathrm{H}_{2} \mathrm{O}\right]_{6}\right)^{3+}$ and other monomeric iron complexes including the anions of the salt that is being used, mostly $\mathrm{FeCl}_{3}$ or $\mathrm{Fe}\left(\mathrm{NO}_{3}\right)_{3}$. Nucleation is initiated by neutralization upon addition of $\mathrm{OH}^{-}$molecules that bind with $\mathrm{Fe}^{3+}$ ions. The thus formed iron-hydroxyl monomers diffuse, and form dimers and probably larger oligomers, which at large enough $\mathrm{OH}^{-}$concentration aggregate into ironpolymeric seeds. ${ }^{15-18}$ Any of these processes can be controlled by the $[\mathrm{OH}] /[\mathrm{Fe}]$ ratio ( $h$, following the notation in ref. 19), which depends on the base that is used, typically $\mathrm{NaOH}$ or the weaker base $\mathrm{NaHCO}_{3}$, and on the concentration of the iron salt.

The solid-phase products, forming for $h>0.5$ in iron aqueous solutions, have been exhaustively studied to explore structure, size, 
and morphology. ${ }^{15,16,18-25}$ Experimental methods applied include titration, UV-vis spectroscopy, ${ }^{26,27}$ wide- and small-angle X-ray scattering (WAXS and SAXS), ${ }^{19,28,29}$ X-ray absorption (XA) spectroscopy, ${ }^{19,20,23,24,26,29-32}$ and electron microscopy. ${ }^{33}$ In the case of $\mathrm{FeCl}_{3}$ aqueous solutions, the different experiments find that akaganeite $(\beta-\mathrm{FeOOH})$ forms, for $h>0.5^{1,25,34}$ Chloride ions were concluded to have a structure-driving effect during formation of akaganeite, ${ }^{20,35-38}$ and yet the exact mechanism remains to be resolved. One likely scenario is that the $\mathrm{Cl}^{-}$ ion is incorporated into the structure at the stage of polynuclear complex formation, and is released when larger aggregates form. ${ }^{38}$ Another work assigns $\mathrm{Cl}^{-}$to defined positions in the mono- and polynuclear complexes. ${ }^{20,24,39}$ With further polymerization edge- and corner-sharing clusters, stabilized by $\mathrm{Cl}^{-}$, were proposed. Eventually, cylindrically-shaped akaganeite seeds form, possibly stabilized by $\mathrm{Cl}^{-}$in the inner coordination spheres. At yet further advanced aggregation more complex shapes are adopted, with only little amount of $\mathrm{Cl}^{-}$in the very vicinity of iron. These observations are in agreement with very recent molecular dynamics simulations exploring counter-ion specific effects. ${ }^{18}$ $\mathrm{Cl}^{-}$is suggested to accommodate in the first solvation shell, thereby favoring a chain-like polymeric structure during condensation reactions. In the absence of $\mathrm{Cl}^{-}$-iron interactions, on the other hand, ring-like structures are favored.

Unlike the formation of particles, our understanding of the transformation of monomeric Fe-oxohydroxy species in $\mathrm{FeCl}_{3}$ aqueous solution, occurring for $h<0.5$, is surprisingly poor. In fact, there is not even an unequivocal experimental evidence for the existence of iron oligomers larger than the dimer, although the occurrence of trimers has been suggested. ${ }^{16,18,20,31,32}$ The uncertainty regarding the existence of the larger oligomers is due to the different experimental conditions that have been applied to probing the liquid solutions. Early X-ray absorption spectroscopy measurements were conducted from freeze-dried $\mathrm{FeCl}_{3}$ aqueous solutions, $0<h<2.8 .^{20,24,39}$ In those studies monomeric iron species, $\mathrm{FeCl}_{2}\left(\mathrm{H}_{2} \mathrm{O}\right)_{4}$, have been identified, and the subsequent elimination of $\mathrm{Cl}^{-}$from the first solvation shell was observed for increased polymerization. The authors further concluded that the monomeric species condense into iron dimers as well as trimers. ${ }^{20}$ A very recent in situ XA spectroscopy study combined with density functional theory (DFT) electronic structure calculations suggests that $\mathrm{Fe} \mu$-oxo bridged dimers form in the case of $\mathrm{Cl}^{-}$as well as for $\mathrm{NO}_{3}{ }^{-}$and $\mathrm{ClO}_{4}{ }^{-}$, not though for $\mathrm{SO}_{4}{ }^{2-}$, in a $\mathrm{pH}$ range of 1.0-2.2. ${ }^{31}$ Based on their computations the authors speculate that there could be also a significant concentration of iron trimers during hydrolysis, but as noted above there is no unambiguous experimental evidence. A similar conclusion has been drawn from a combined X-ray (again in situ), UV-vis, and Mössbauerspectroscopy study on the precipitation pathways for ferrihydrite formation in acidic solution from iron nitrate. ${ }^{19}$ The authors have shown that iron exists mainly as monomer, $\mu$-oxo aqua dimers, and the solid ferrihydrite. Again, no larger iron-oxo oligomers were detected, suggesting the reconfiguration of the $\mu$-oxo dimer structure prior to further nucleation.

Up to this point we have not accounted for the lifetimes of the iron-oxo oligomers which may be too short for these species to be detected with the aforementioned experimental techniques that probe minutes or hours after solution preparation. In a theoretical molecular dynamics simulation of iron solutions the reactions beyond dimer formation were indeed found to happen in just tens of picoseconds. ${ }^{18}$ Also, experiments on iron perchlorate solutions report fast rate constants for dimer formation of $400 \mathrm{M}^{-1} \mathrm{~s}^{-1}$ implying that the larger oligomers form rapidly as well. ${ }^{1,40}$ Such fast kinetics will affect the subsequent nucleation and aggregation reactions, and suggests that small iron oligomers, dimers, trimers, tetramers, and perhaps even larger ones, are too short-lived to be detected. We note that unlike for other metal ions, such as $\mathrm{Cr}^{3+}, \mathrm{Al}^{3+}$, or $\mathrm{Rh}^{3+}$, reactions are particularly fast for $\mathrm{Fe}^{3+} \cdot 41,42$

In the present study, we measured soft-X-ray photoelectron (PE) spectra from a liquid microjet to determine the electronic structure of the iron-oxo species in $\mathrm{FeCl}_{3}$ aqueous solution, for $h<0.5$. That is, unlike most previous X-ray studies, experiments are conducted directly from the aqueous solution rather than from dried phase. Furthermore, we here detect emitted electrons rather than transmitted or scattered X-rays. This is also the first X-ray (photoemission) study detecting signal from iron-oxo oligomers at the oxygen 1s edge.

Measurements were performed for non-resonant and resonant photon energies, where the latter refers to excitations at the oxygen 1s (near $530 \mathrm{eV}$ photon energy) and Fe 2p (near $705 \mathrm{eV}$ ) edges, respectively. This is also different from any previous works, reporting Fe 1s-edge transmission XA spectra, and more importantly, in measuring photoelectron spectra also from oxygen complementary important spectroscopic information is obtained. By integration of the signal of the resonant photoelectron (RPE) spectra we generate the so-called partial-electron-yield X-ray absorption (PEY-XA) spectra. To first approximation these spectra are a good representation of the actual X-ray absorption which would be accurately measured in X-ray transmission, ${ }^{43}$ and the assumption is that the absorption is proportional to the number of emitted Auger electrons. ${ }^{43}$ By comparing PEY-XA spectra from the partially hydrolyzed solutions with the spectrum from $\mathrm{Fe}^{3+}(\mathrm{aq})$, obtained from the $\mathrm{FeCl}_{3}$ solution with no $\mathrm{OH}^{-}$added, we unequivocally determine the X-ray absorption of the iron-oxo oligomers. Yet, more important, from the respective RPE spectra we directly identify the valence orbitals, and their mixed iron-oxygen character, which are responsible for the absorption. To support our interpretation of the PE and the PEY-XA spectra we also conducted Raman and small-angle X-ray scattering (SAXS) measurements from the same aqueous solutions. Raman spectra are compared with reported spectra from well characterized iron-oxide phases to identify and assign structure motifs of the oligomers. SAXS, on the other hand is used to detect particles, and most important for this study the $h$ ratio at which small particles begin to form can be determined.

\section{Experimental}

\subsection{Preparation of iron aqueous solutions}

Stock solutions of $1.9 \mathrm{M} \mathrm{FeCl}_{3} \cdot 6 \mathrm{H}_{2} \mathrm{O}$ and $3.8 \mathrm{M} \mathrm{NaOH}$ were prepared from $\mathrm{FeCl}_{3} \cdot 6 \mathrm{H}_{2} \mathrm{O}$ (purity $\geq 99 \%$; Sigma Aldrich) 
powder and $\mathrm{NaOH}$ pellets (purity $\geq 98 \%$; Sigma Aldrich) without further purification. Water (Millipore; $18.2 \mathrm{M} \Omega \mathrm{cm}^{-1}$ ) was flushed with nitrogen for $>12 \mathrm{~h}$ before being used. The final concentration of the $\mathrm{FeCl}_{3} \cdot 6 \mathrm{H}_{2} \mathrm{O}$ solution studied here was $0.75 \mathrm{M}$. $[\mathrm{OH}] /[\mathrm{Fe}](=h)$ ratios, from $0-2.5$, were adjusted by addition of a defined amount of $\mathrm{NaOH}$ solution to water, and this solution is then added to a constant fraction of $\mathrm{FeCl}_{3} \cdot 6 \mathrm{H}_{2} \mathrm{O}$ under vigorous stirring. A scheme of the preparation procedure is shown in Fig. SI-1 (ESI $\dagger$ ), and the mixing ratios of the different solutions are presented in Table SI-1 (ESI $\dagger$ ). For the photoelectron-spectroscopy experiments $100 \mathrm{ml}$ solutions were prepared, whereas for Raman and SAXS measurements $5 \mathrm{ml}$ were sufficient.

For each aqueous solution, i.e., for each $h$, the $\mathrm{pH}$ was measured for different (aging) times, $15 \mathrm{~min}, 1 \mathrm{~h}$, and $24 \mathrm{~h}$, after preparation. We used an InLab Semi-Micro-L pH electrode (Mettler Toledo, Gießen, Germany) which was calibrated with buffer solutions of pH 2.00, 4.01 and 7.00.

\subsection{Photoelectron spectroscopy measurements}

Photoelectron spectroscopy measurements were performed at the U49/2-PGM-1 soft-X-ray undulator beamline at the synchrotron radiation facility BESSY II in Berlin, Germany. The liquid microjet with a diameter of $24 \mu \mathrm{m}$ was injected into the vacuum chamber from a fused-silica nozzle. The jet velocity was approximately $40 \mathrm{~ms}^{-1}$, and the jet temperature was kept at $8{ }^{\circ} \mathrm{C}$. Details of the liquid microjet technique and of the experimental setup have been described previously. ${ }^{44-46}$ The energy resolution of the U49/2-PGM-1 beamline was better than $250 \mathrm{meV}$ at $530 \mathrm{eV}$ photon energy used for the oxygen $\mathrm{O}$ 1s resonant valence $\mathrm{PE}$ measurements, and $\sim 380 \mathrm{meV}$ at $710 \mathrm{eV}$ photon energy needed for the $\mathrm{PE}$ measurements at the $\mathrm{Fe} 2 \mathrm{p}_{3 / 2}$ absorption edge. This beamline provides a suitably small focal size of $20 \times 80 \mu \mathrm{m}^{2}$ at high photon flux, assuring that the (water) gas-phase signal contribution to the total (photo)electron signal is much smaller than the signal from aqueous phase. The energy resolution of the hemispherical electron analyzer, $\sim 250 \mathrm{meV}$ at $30 \mathrm{eV}$ pass energy, was constant with kinetic energy (KE). Oxygen 1s resonant spectra were calibrated with reference to the water valence $1 b_{1}$ peak, which is $11.31 \mathrm{eV}$ binding energy, and Fe $2 \mathrm{p}_{3 / 2}$ resonant spectra were calibrated against the $\mathrm{O} 1 \mathrm{~s}$ binding energy of water, which is $538.1 \mathrm{eV} .^{47,48}$

\subsection{Raman spectroscopy measurements}

Raman spectra were collected for aqueous solutions in the range of $0.0 \leq h \leq 2.5$. Measurements were performed with a LabRam HR800 spectrometer (Horiba Jobin Yvon, Bensheim, Germany), equipped with a $633 \mathrm{~nm}$ HeNe laser (Horiba Jobin Yvon, Bensheim, Germany), a 300 lines per mm grating, and a BX41 microscope (Olympus, Hamburg, Germany). The backscattered Raman light was collected by a liquid nitrogen-cooled CCD detector $(1024 \times 256$ pixels, Horiba). Using a $60 \times$ immersion objective, the laser intensity at the liquid sample was $5.09 \times$ $10^{5} \mathrm{~W} \mathrm{~cm}^{-2}$. Reported Raman spectra are averages of five sweeps, each recorded with an acquisition time of $10 \mathrm{~s}$. All measurements were performed $1 \mathrm{~h}$ after solution preparation.

\subsection{Small-angle X-ray scattering measurements}

Scattering curves were measured for $0.05 \leq h \leq 1$ using a laboratory SAXS instrument (SAXSess, Anton Paar, Graz, Austria), equipped with a sealed X-ray tube (Cu anode target, $\lambda=1.5406 \AA$ ). A flow-quartz capillary with a thickness of $1 \mathrm{~mm}$ was used as sample holder. SAXS data from the hydrolyzed solutions are presented with the spectrum measured for $h=0$ subtracted and were corrected for the slit smearing effect. Data were fitted to scattering curves within a cylinder model and a Schulz distribution for the radius, using the SANS Analysis_v3.00 tool implemented in the software package IGOR PRO. ${ }^{49}$ More information about the fitting model can be found in the ESI. $\dagger$

\section{Results and discussion}

We first present the evolution of $\mathrm{pH}$ as function of both $h$ and time. This is followed by a presentation and discussion of the various photoemission spectra, i.e., on- and off-resonant valence PE spectra, and the resulting PEY-XA spectra. We then show results from Raman and SAXS measurements, and discuss the complementary information one obtains on the structure of the iron-oxo oligomers and their aggregation.

\section{1 pH dependence on $h$ and aging time}

The $[\mathrm{OH}] /[\mathrm{Fe}]=h$ ratios and $\mathrm{pH}$ are directly connected, and the quantitative relation provides a first qualitative hint at the role $\mathrm{OH}^{-}$plays in the nucleation and aggregation processes. Results are shown in Fig. 1, where we present pHs for $0<h<2.5$, measured for different aging times, from $15 \mathrm{~min}$ to $24 \mathrm{~h}$. For all aging times studied $\mathrm{pH}$ rises steeply from 1.0 to 1.4 for a very small initial increase of $h$, from 0 to 0.2 , marked as region I in the figure. Time depending aging effects set in at $h>0.2$ as will be discussed below. The solutions measured $15 \mathrm{~min}$ after preparation exhibit a continuous steady increase of $\mathrm{pH}$ in the region of $0.25<h<0.5$; this is region II in the figure. For $h>0.5$ the

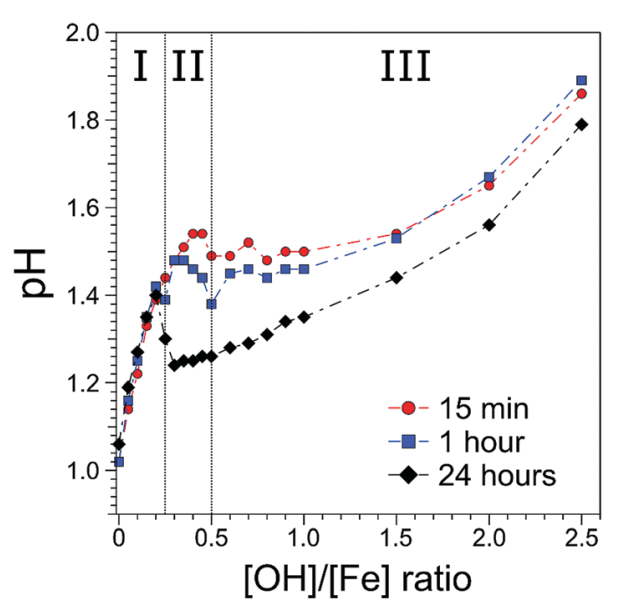

Fig. 1 Evolution of $\mathrm{pH}$ of $0.75 \mathrm{M} \mathrm{FeCl}_{3}$ solutions as a function of $h=[\mathrm{OH}] /[\mathrm{Fe}]$ ratio. Regions I-III correspond to the transitions from monomeric iron species to iron-oxo oligomers, and finally iron-oxo solid particles. Region I: oligomers with $<1 \mathrm{~nm}$ diameter. Region II: cylindrical particles. Region III: cylindrical particles and akaganeite formation. 
$\mathrm{pH}$ stays rather constant (near 1.5) up to $h=1.5$, upon further addition of $\mathrm{NaOH}$, corresponding to $h>1.5 \mathrm{pH}$ rises again. We call this region III, explored here up to $h=2.5$. The behavior of the $60 \mathrm{~min}$ solutions is rather similar, but the plateau (region II) appears to set in somewhat earlier, at $h=0.3$, and $\mathrm{pH}$ is slightly smaller $(\approx 1.45)$ than for the 15 min solution. More prominent differences occur for the 24 hour solutions, where the $\mathrm{pH}$ suddenly drops from 1.4 to approximately 1.2, right at the border between regions I and II, and then steadily rises through regions II-III, but the solutions stay always more acidic than for the shorter aging times. The observed timeindependent $\mathrm{pH}$ increase (region I) implies that not all $\mathrm{OH}^{-}$ molecules are being consumed in the formation of iron-hydroxide complexes, but rather neutralize protons $\left(\mathrm{H}_{3} \mathrm{O}^{+}(\mathrm{aq})\right)$ to form water. The time independent behavior further suggests that stable compounds, most likely monomeric iron-(III) complexes exist in region I. The time-dependent pHs (regions II-III), on the other hand must be assigned to an increasing consumption of $\mathrm{OH}^{-}$the longer the reaction proceeds, which we tentatively attribute to the formation of iron-oxide hydroxide polynuclear compounds (transition region I-II) and particles (region II-III). The SAXS measurements indicate that particles begin to form in region II. The constant and reduced $\mathrm{pH}$ (region III) can be explained by an exchange of $\mathrm{Cl}^{-}$and $\mathrm{H}_{2} \mathrm{O}$ in the complexes for $\mathrm{OH}^{-}$from solution. Alternatively, one can envision an indirect process where added $\mathrm{OH}^{-}$are neutralized by protons stemming from condensation reactions of iron monomers or from deprotonation reactions of the clusters. From our discussion of the $\mathrm{pH}$ behavior we then expect to detect iron-oxo oligomers at the transition from region I to II, i.e., in a regime where particles are yet absent, and the concentration of the seeds being probably largest.

\subsection{Photoemission spectra from solutions}

Oxygen-1s resonant PE spectra and PEY-XA spectra. Fig. 2A presents partial electron yield X-ray absorption (PEY-XA) spectra at the oxygen 1s edge, covering the 527-547 eV photon energy range, from $0.75 \mathrm{M} \mathrm{FeCl}_{3}$ solutions for $h=0,0.15,0.25,0.35$, and 0.5. For comparison, PEY-XA spectra are also shown from neat liquid water as well as from $35 \% \mathrm{NaOH}$ aqueous solution. The spectra are obtained by integration of the respective valence resonant photoemission signal intensities in the $470-530 \mathrm{eV}$ kinetic-energy range; a given PEY-XA spectrum thus results from the intensity changes among the RPE spectra. ${ }^{50}$ More precisely, the signal due to emission of Auger electrons that overlaps with the valence photoelectron spectrum (at resonance) is approximately proportional to the X-ray absorption. ${ }^{43}$ But more interesting is the fact that the intensity of photoelectron peaks that correspond to the ionization of a given orbital can get enhanced due to the interference of Auger electron and direct photoelectron channels. By such a signal enhancement we can then identify the overlap of orbitals (or electron delocalization) ${ }^{50,51}$ from the oligomers and water, and obtain valuable insight into electronic-structure interactions.

From Fig. 2A we see that the PEY-XA spectra from the iron aqueous solutions are very similar to the neat-water XA spectrum with its characteristic pre-edge at $535.0 \mathrm{eV}$, main edge $(538.0 \mathrm{eV})$, and post-edge $(541.0 \mathrm{eV}) .{ }^{52}$ The most important, although very small spectral difference though is the intensity growing in near $529.5 \mathrm{eV}$ (referred to as peak $\boldsymbol{a}$ ), which is well
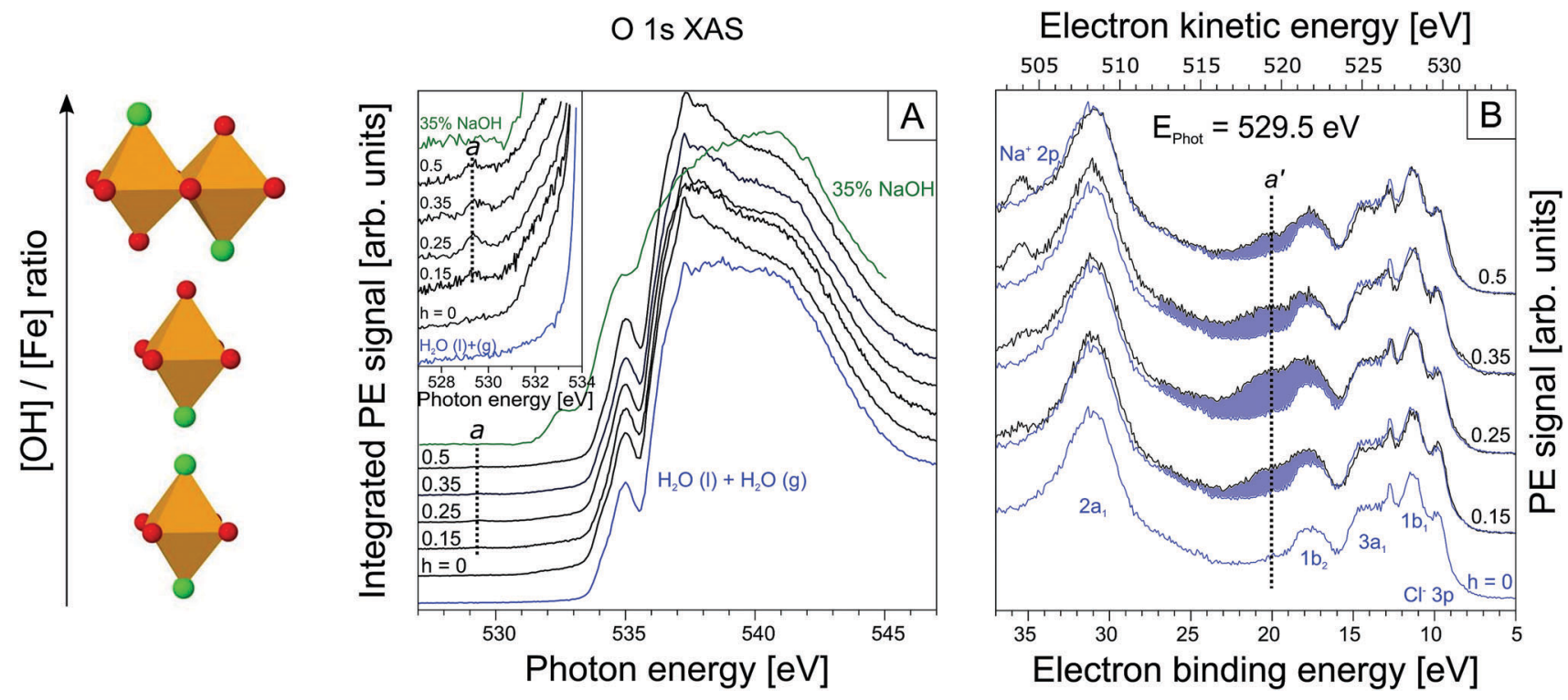

Fig. 2 (A) Oxygen 1s PEY-XA spectra from $\mathrm{FeCl}_{3}$ solutions for $h=0,0.15,0.25,0.35,0.5$. For comparison, spectra from neat water (in blue) and from a $35 \mathrm{wt} \% \mathrm{NaOH}$ aqueous solution (in green) are also presented. The low-energy shoulder on the $535 \mathrm{eV}$ pre-peak visible in all spectra is due to gas-phase water. The inset shows an enlarged view of the spectral region of a centered at $529.5 \mathrm{eV}$ photon energy. (B) Resonant valence PE spectra measured at $529.5 \mathrm{eV}$ from the same $0.75 \mathrm{M} \mathrm{FeCl}_{3}$ aqueous solutions, $0 \leq h \leq 0.5$, as in (A). Spectra were energy-calibrated with the help of the $1 b_{1}$ energy of water, and intensities are displayed such that the height of the $\mathrm{Cl}^{-} 3 p$ peak at $9.6 \mathrm{eV}$ binding energy is the same. The reference spectrum from the $h=0$ solution (in blue at bottom) is reproduced in all traces to highlight the spectral differences as a function of $h$ (blue-shaded areas). The sketch at left indicates the formation of the iron-oxo oligomers with increasing $h$. 
below the water XA onset; an enlarged view of this spectral region is presented in the inset of Fig. 2A. Absorption $\boldsymbol{a}$ clearly arises from some iron-oxide species. Spectral contribution from $\mathrm{OH}^{-}$(aq) can be ruled out; the lowest-energy absorption for the $\mathrm{NaOH}$ aqueous solution (in green) is at $532.5 \mathrm{eV}$. We also note that the first-hydration-shell water molecules in $\left(\mathrm{Fe}\left(\mathrm{H}_{2} \mathrm{O}\right)_{6}\right)^{3+}$ (aq) absorb at considerably larger energy than $\boldsymbol{a}$, at $531.0 \mathrm{eV} .^{53}$ Another important observation from the inset in Fig. 2A is that peak $\boldsymbol{a}$ only exists in a small $h$ window, exhibiting maximum intensity at $h=0.25$. With reference to Fig. 1 , this is exactly the ratio at which the transition from time-independent to timedependent behavior of $\mathrm{pH}$ (going from I to II) is observed. In Section 3.1 we have argued that this is the region where the oxooligomers have not yet aggregated to form particles.

Up to this point we have solely evaluated the O 1s PEY-XA spectra without aid of the respective RPE spectra. As aforementioned the PEY-XA spectra are proportional to the emitted Auger-electron intensities at resonance, but there is an additional signal contribution which manifests in an intensity increase of certain binding energy features in the RPE spectra. These are fingerprints of oxygen-iron orbital mixing ${ }^{43}$ which we will explain when presenting the RPE spectra measured at the photon energy $529.5 \mathrm{eV}$, corresponding to absorption $\boldsymbol{a}$. Results are shown in Fig. 2B for the same solutions, i.e. same $h$ ratios, as in Fig. 2A. The bottom spectrum (in blue) is essentially the valence $P E$ spectrum of neat liquid water with its four valence orbitals, $1 \mathrm{~b}_{1}$ (11.31 eV binding energy), $3 \mathrm{a}_{1}(13.5 \mathrm{eV} \mathrm{BE})$, $1 \mathrm{~b}_{2}$ (17.5 eV BE), and $2 \mathrm{a}_{1}(30.5 \mathrm{eV} \mathrm{BE}) .{ }^{47,54}$ Contributions from $\mathrm{FeCl}_{3}$ are small; the only noticeable signal is the $\mathrm{Cl}^{-} 3 \mathrm{p}$ doublet at 9.6 eV.$^{55-58}$ The small electron signal from $\mathrm{Fe}^{3+} 3 \mathrm{~d}$ ionization is partially hidden underneath the $1 b_{1}$ peak of water. ${ }^{59,60}$ When increasing the $\mathrm{OH}^{-}$concentration to yield $h=0.15$ one observes the appearance of a broad spectral feature in the 17-27 eV BE range. The largest intensity increase occurs at $21 \mathrm{eV} \mathrm{BE}$, labeled $\mathrm{a}^{\prime}$ in the figure. This spectral region can be assigned to $\mathrm{O} 1 \mathrm{~s}$ spectator Auger decay, and refers to the promotion of an $\mathrm{O} 1 \mathrm{~s}$ electron (at $529.5 \mathrm{eV}$ excitation energy) of an iron-oxo oligomer to an unoccupied molecular state below the vacuum level. The O 1s core-hole is subsequently refilled by a valence electron within the few-femtoseconds lifetime, and the released energy is used to eject another valence electron into vacuum. ${ }^{61,62}$ To further characterize the iron-oxide oligomers that give rise to XA-peak $\boldsymbol{a}$, and which are also responsible for PE peak $\boldsymbol{a}^{\prime}$ we need to also investigate the iron resonances. Here, we are particularly interested in a signature of $\boldsymbol{a}^{\prime}$, associated with oxygen-iron mixed orbitals.

Iron-2p resonant PE spectra and PEY-XA spectra. Fig. 3A presents PEY-XA spectra at the iron $2 p$ edge (only $2 \mathrm{p}_{3 / 2}$ was measured) from the same solutions for which $O$ 1s spectra (Fig. 2A and B) have been recorded. The spectrum from the $h=0$ solution (in blue) is reproduced in each tier so that the spectral changes become more visible. Spectra were obtained by signal integration of the (valence) resonant PE spectrum measured at the respective photon energy, varied here from 706.5 to $717.0 \mathrm{eV}$. The integration range of the RPE spectra was 6-43 eV BE (equivalent to $\sim 660-700 \mathrm{eV} \mathrm{KE}$ ) which covers the region of the $2 \mathrm{p}-3 \mathrm{~d} 3 \mathrm{~d}$ Auger-electron emission. All XA spectra exhibit the double-peak structure characteristic of $\mathrm{Fe}^{3+}$, i.e., a smaller pre-peak near $708.9 \mathrm{eV}$ and main peak at $710.7 \mathrm{eV}$ photon energy. These absorptions result from the excitation of an $\mathrm{Fe} 2 \mathrm{p}_{3 / 2}$ electron into the $\mathrm{t}_{2 \mathrm{~g}}$ and $\mathrm{e}_{\mathrm{g}}$ valence levels, respectively, of the octahedrally coordinated iron cation. ${ }^{50,63,64}$ The intensity giving rise to the asymmetric shoulder near $712 \mathrm{eV}$ photon energy is commonly attributed to charge-transfer states
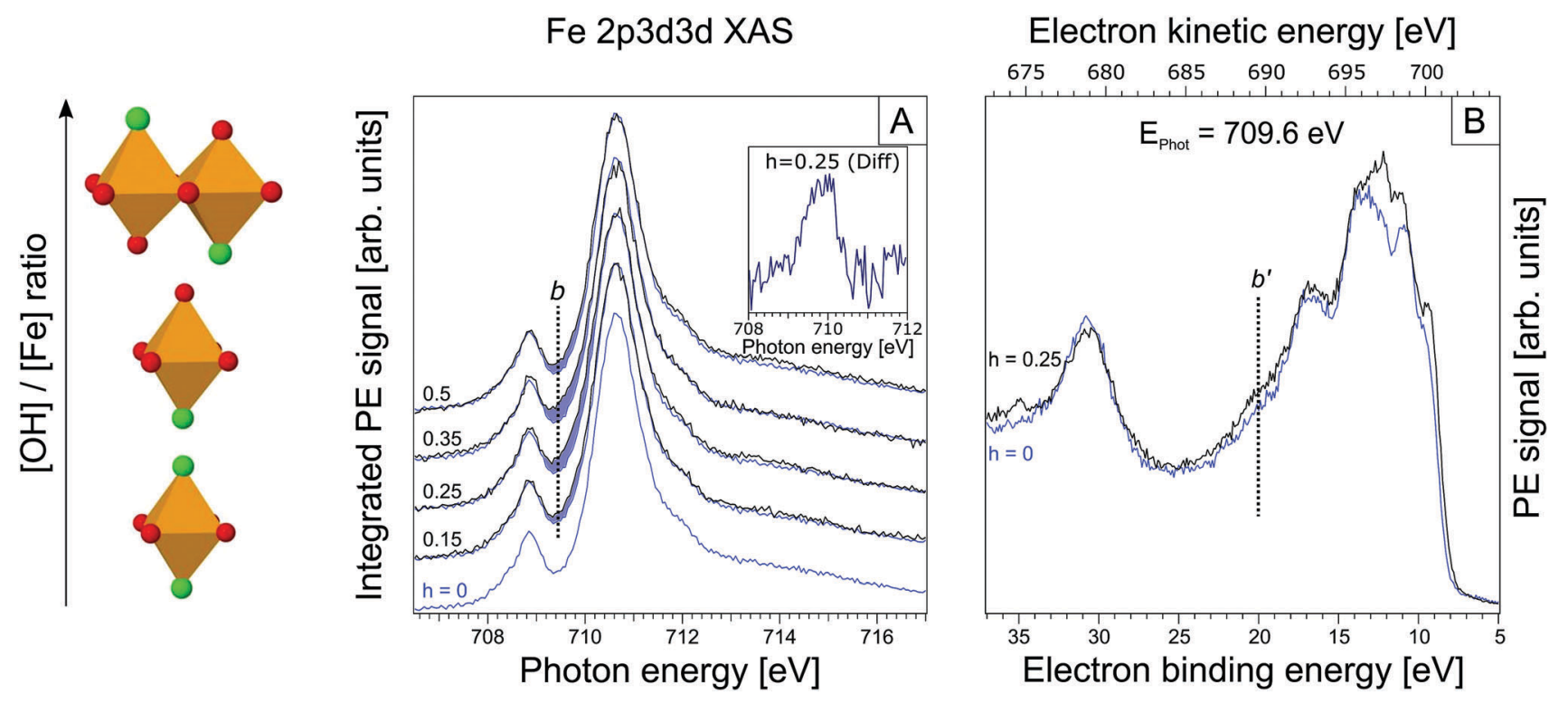

Fig. 3 (A) Partial electron yield X-ray absorption spectra at the iron $2 p_{3 / 2}$. The $h=0$ XA spectrum is reproduced in each tier for $h \neq 0$. Again, spectral differences are highlighted in blue. The inset displays the actual differential spectrum for $h=0.25 ; \boldsymbol{b}$ is the maximum of this absorption band. (B) RPE spectrum for $h=0.25$ solution, measured at $709.6 \mathrm{eV}$ excitation photon energy (maximum of the main absorption band in Fig. 3A). In blue the RPE spectrum for $h=0$ is shown. 
between the iron and the ligand $;^{50,65}$ for $h=0$ the ligands are the hydration water molecules. As seen in Fig. 3A, the most noticeable spectral change as a function of $h$ is a signal increase occurring between 709.0 and $710.4 \mathrm{eV}$ excitation energy. The difference spectrum, $h=0.25$ solution minus $h=0$ solution, presented in the inset of Fig. 3A, reveals an absorption band (labeled $\boldsymbol{b}$ ) with a maximum at $709.6 \mathrm{eV}$. Absorption $\boldsymbol{b}$ is largest for $h=0.25-0.35$ which is the same range where we find the $\mathrm{O} 1 \mathrm{~s}$ absorption, $\boldsymbol{a}$, suggesting that iron absorption b originates from the same species. To demonstrate that this is indeed the case we next explore the iron 2p RPE spectra. Fig. 3B presents the $709.6 \mathrm{eV}$ (absorption $\boldsymbol{b}^{\prime}$ ) RPE spectra for $h=0.25$ and $h=0$, respectively. The important observation is a slightly larger signal intensity near $20 \mathrm{eV}$ BE for the former solution. This feature is similarly broad and is also located at the very similar binding energy as $\boldsymbol{a}^{\prime}$ in the O 1s RPE spectra which not only confirms that $\mathrm{O} 1 \mathrm{~s}$ and Fe 2p spectroscopies probe the same iron-oxo species, it also reveals the hybridization between iron and oxygen orbitals. Structure information is revealed from our Raman measurements discussed next.

\subsection{Raman measurements}

Raman spectra, recorded for $0.75 \mathrm{M} \mathrm{FeCl}_{3}$ with $0<h<2.5$, are shown in Fig. SI-2 (ESI $\dagger$ ). Fig. SI-2A (ESI $\dagger$ ) presents the measured spectra from which a linear background, determined from extrapolation of the linear slope between $1100 \mathrm{~cm}^{-1}$ and $1550 \mathrm{~cm}^{-1}$, has been subtracted. The spectra are also displayed to yield the same peak height at $188 \mathrm{~cm}^{-1}$; Fig. SI-2B (ESI $\dagger$ ) shows the same spectra but with the $h=0$ reference spectrum subtracted. The spectra of $\mathrm{FeCl}_{3}(\mathrm{aq})$ with no $\mathrm{NaOH}$ added $(h=0)$ in Fig. SI-2A (ESI $\dagger$ ) exhibit the Raman bands characteristic for ferric chloride, at $188 \mathrm{~cm}^{-1}, 320 \mathrm{~cm}^{-1}, 480 \mathrm{~cm}^{-1}$, and $1650 \mathrm{~cm}^{-1} \cdot{ }^{66}$ Bands below $200 \mathrm{~cm}^{-1}$ are the translational vibrations of hydrogen bonded $\mathrm{H}_{2} \mathrm{O}-\mathrm{H}_{2} \mathrm{O}$ or Cl- $\mathrm{H}_{2} \mathrm{O}$ motifs. ${ }^{66,67}$ The $320 \mathrm{~cm}^{-1}$ band is generally assigned to $\mathrm{Fe}-\mathrm{Cl}$ stretching vibrations, ${ }^{66,68,69}$ and the shoulder at $440-480 \mathrm{~cm}^{-1}$ is due to the $\mathrm{Fe}-\mathrm{OH}_{2}$ stretch. ${ }^{66}$ The broad band at $1650 \mathrm{~cm}^{-1}$ corresponds to the water $\nu_{2}$ bending vibration. ${ }^{67,70}$ In contrast, Raman spectra measured at the large ratio $h=2.5$ exhibit additional bands characteristic for akaganeite, at 395 (Fe-OH), 550 and $720 \mathrm{~cm}^{-1}$ (FeOOH). ${ }^{69}$ Furthermore, the occurrence of $\boldsymbol{a}$ band at $866 \mathrm{~cm}^{-1}$ with maximum intensity near $h=0.25$ can be probably assigned to Fe-O-Fe motifs in dinuclear complexes. ${ }^{68,71}$ A compilation of the significant Raman bands observed here, and their assignments are given in Table SI-2 (ESI $\dagger$ ).

To quantify the spectral changes, we plot in Fig. SI-3 (ESI $\dagger$ ) the evolution of the relative intensities of the experimental Raman shifts as a function of $h$. In region I $(0<h<0.25$; compare Fig. 1) one observes a decrease of the $320 \mathrm{~cm}^{-1}(\mathrm{Fe}-\mathrm{Cl})$ band, indicative of bound $\mathrm{Cl}^{-}$being replaced by $\mathrm{OH}^{-}$from solution. Such ligand exchange is corroborated by the rising $395 \mathrm{~cm}^{-1}$ (Fe-OH) band intensity, accompanied by an increase of the $866 \mathrm{~cm}^{-1}$ (Fe-O-Fe) band. This may be an indication of the existence of dinuclear iron species linked by oxygen. But structure details cannot be inferred from the spectra. The $188 \mathrm{~cm}^{-1}$ $\left(\mathrm{H}_{2} \mathrm{O}-\mathrm{H}_{2} \mathrm{O}, \mathrm{H}_{2} \mathrm{O}-\mathrm{Cl}\right.$ vibrations $)$ and $1650 \mathrm{~cm}^{-1}\left(\mathrm{H}_{2} \mathrm{O}\right)$ solvent band intensities are seen to stay unaffected by the iron complexation which can be explained by the much larger number of solvent molecules than iron complexes. Finally, one notices that akaganeite-related vibrations $\left(550 \mathrm{~cm}^{-1}\right.$ and $\left.720 \mathrm{~cm}^{-1}\right)$ are not observed in region I, exactly as expected from our conclusions drawn in Sections 3.1 and 3.2 whereupon particles occur in region II $(0.25<h<0.5)$. Indeed the $395 \mathrm{~cm}^{-1}(\mathrm{Fe}-\mathrm{OH})$ and the $866 \mathrm{~cm}^{-1}$ (Fe-O-Fe) band intensities in region II decrease, and both the $550 \mathrm{~cm}^{-1}$ and $720 \mathrm{~cm}^{-1}$ akaganeite signals emerge. These observations indicate the formation of larger aggregates, consistent with our qualitative conclusions drawn from the $\mathrm{pH}$ changes (Fig. 1). Another important observation from Fig. SI-3 (ESI $\dagger$ ) is the intensity increase of the $320 \mathrm{~cm}^{-1}$ (Fe-Cl) band, indicating that the larger oligomers arrange around $\mathrm{Cl}$, which is in accord with the structure-driving nature of $\mathrm{Cl}^{-}$in the formation of akaganeite. Finally, region III $(0.5<h<1.5)$ reveals a simultaneous increase of the $395 \mathrm{~cm}^{-1}, 550 \mathrm{~cm}^{-1}$ and $720 \mathrm{~cm}^{-1}$ bands, which are the signatures of akaganeite. The constant intensities of the solvent vibrational bands $\left(188 \mathrm{~cm}^{-1}\right.$ and $\left.1650 \mathrm{~cm}^{-1}\right)$ in region III indicates that the properties of the solvent vibrations do not change. The $\mathrm{Fe}-\mathrm{Cl}$ band $\left(320 \mathrm{~cm}^{-1}\right)$ is seen to decrease in region III suggesting that $\mathrm{Cl}^{-}$is partially expelled in later stages of the akaganeite formation, a conclusion that has been also drawn from ref. 38 as mentioned in the introduction.

\subsection{SAXS measurements}

To evaluate the onset of particle formation SAXS measurements were performed for $0.05<h<1.5$. Results are shown exemplary for $h=0.25,0.3,0.5$ and 1.0 in Fig. SI-4 (ESI $\dagger$ ), where the scattering intensities are presented with the $h=0$ scattering intensities subtracted. As can be seen, for $h \leq 0.25$ (region I) only noise is being detected implying that no particles are present in the solutions; zero signal is exactly what we expect based on the $\mathrm{pH}$ changes and on the photoemission data. Scattering from particles sets in at $h=0.3$ (mid-range region II); see the red curve in Fig. SI-4 (ESI $\dagger)$. This is also consistent with both our photoemission and Raman data. For larger $h$ the scattering intensity increases. Scattering curves for the solutions, shown by the solid lines, are the best fits based on a cylinder model (compare Section 2.3). This is an appropriate assumption since akaganeite tends to form by aggregation of rod-like crystals under the present experimental conditions. ${ }^{1}$ From the fit parameters we can determine, for each $h$, the radius and length of the particles. Both quantities are presented in Fig. SI-5A (ESI $\dagger$ ) as a function of $h$. Note that scattering intensities for $h=0.3$ are too noisy to extract a reliable length and radius. The cylindrical particles in the range of $h=0.35-1.5$ (region II and III) solutions are found to have a length of 9.5-12.6 $\mathrm{nm}$ and radius of $\sim 1 \mathrm{~nm}$. The increasing scattering intensities can be attributed to an increasing relative number of the particles rather than to further growth of the particles. The quantitative relation between the relative number of particles and $h$ is shown in Fig. SI-5B (ESI $\dagger$ ).

\section{Conclusions}

We have reported the very first photoelectron spectra from iron-oxo oligomers that form upon hydrolysis in iron aqueous solutions, 


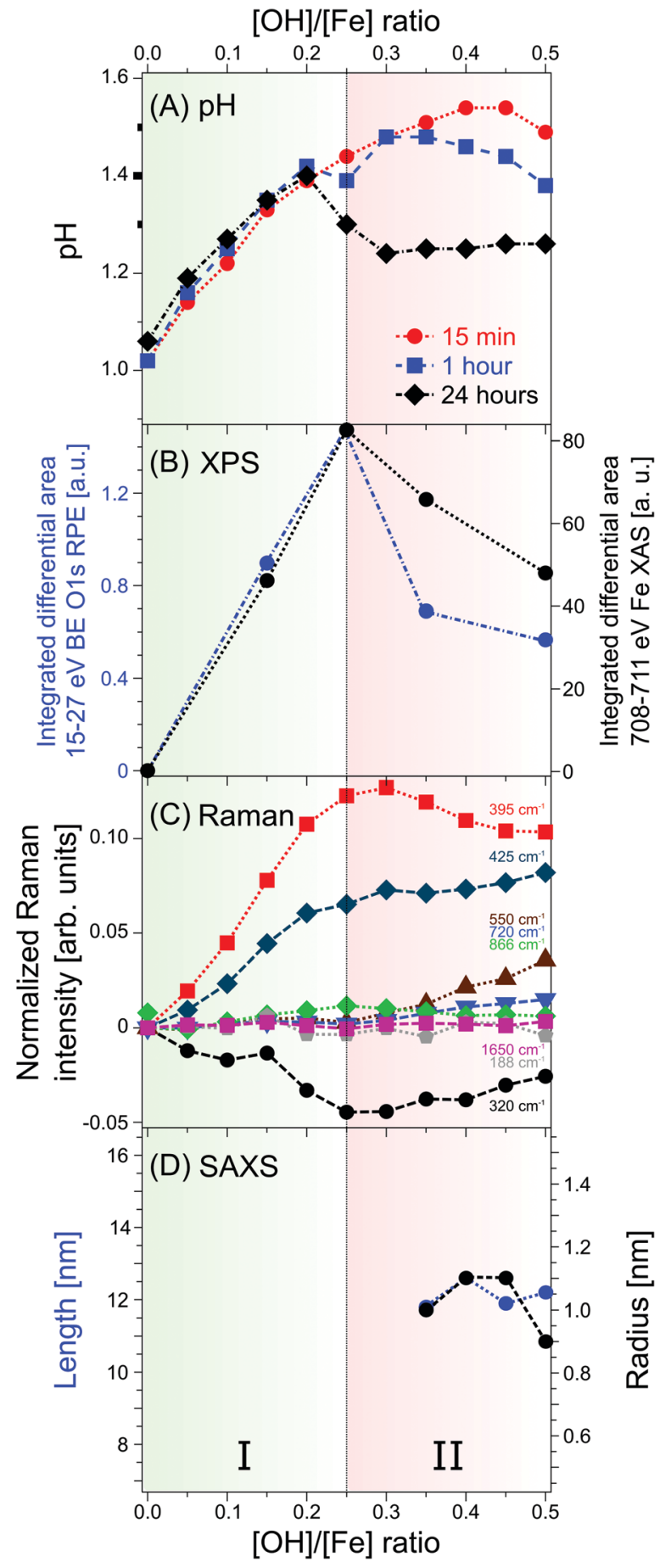

Fig. 4 Summary of trends from the different spectroscopic data as a function of the $h=0-0.5$ (A) pH. (B) Intensities of $a$ and $b$ PEY-XA bands for the $O$ 1s and the Fe $2 p$ edges, respectively. (C) Raman lines. (D) Particle lengths and radii from SAXS measurements.

demonstrated here for $\mathrm{FeCl}_{3}(\mathrm{aq})$ with various amounts of $\mathrm{NaOH}$ added. The main experimental advances of the present work compared to previous X-ray studies are: (i) iron-oxo species are directly probed in aqueous solutions, for the most relevant $[\mathrm{OH}] /[\mathrm{Fe}]$ ratios $h=0-0.5$, using the liquid-microjet technique; (ii) valence electron binding energies have been determined, both the lowest-ionization energy of the aqueous-phase iron-oxo species, and of deeper valence energies; (iii) from a combination of nonresonant and resonant photoelectron spectroscopy, and by probing both the oxygen (1s) and the iron (2p) edges mixed iron-oxygen orbital characters are identified; (iv) X-ray absorption spectra based on partial-electron-yield detection reveal distinct absorptions of the iron-oxo oligomers, at $529 \mathrm{eV}$ for O 1s, and at $709 \mathrm{eV}$ for the Fe 2p resonance. An important future step would be to perform theoretical calculations of the $h=0.25$ XA spectrum for several appropriately guessed oligomeric structures, and find the best match between experiment and theory. Furthermore, to narrow down the search for structures we are preparing to apply ion mobility-mass spectrometry in conjunction with soft-condition electrospray. ${ }^{72}$

In addition to the electronic-structure determination of the ironoxo oligomers we have conducted complementary Raman and SAXS measurements. We summarize our results with Fig. 4 which presents the main and most important trends, revealed from the different experimental methods; here we also include $\mathrm{pH}$ measurements. Our focus stays on the $[\mathrm{OH}] /[\mathrm{Fe}]=h=0-0.5$ which covers the range where the iron-oxo oligomers are stabilized without engaging in further aggregation. One can immediately see from Fig. 4 that a given observable exhibits a discontinuous behavior at $h=0.25$, which in all cases can be attributed to the occurrence of the oligomers. The photoelectron signal (B), of both oxygen and iron, exists only within a small range of $h$, implying that at larger $\mathrm{OH}^{-}$concentrations the oligomers are consumed by aggregation. This is fully confirmed by the $\mathrm{pH}$ (A), Raman (C), and SAXS (D) data. Briefly, the linear behavior of $\mathrm{pH}$ near $h=0.25$ is an indication of continuous hydrolysis and hence formation of iron-oxo oligomers. Departure from linearity is due to $\mathrm{OH}^{-}$molecules reacting with $\mathrm{H}_{2} \mathrm{O}$ molecules, and for large enough $h \mathrm{pH}$ trends can be explained by aggregation. The oligomerto-particle transition is nicely corroborated by the Raman spectra which exhibit $\mathrm{Fe}-\mathrm{O}$ and $\mathrm{Fe}-\mathrm{O}-\mathrm{Fe}$ bands characteristic for the small oligomers. At $h>0.25$, the intensity of these bands decreases on the expense of bands typical for akaganeite. Furthermore, the exclusive existence of small oligomers, i.e., the absence of particles in the $h<0.3$ solutions is confirmed by our SAXS measurements.

The present study demonstrates the large potential of liquidmicrojet photoelectron spectroscopy for detecting the electronic structure of the initial hydrolysis products that govern subsequent nucleation and aggregation processes. Our work lays the ground for similar experiments to characterize the growth processes in other solutions, for instance $\mathrm{Al}^{3+}(\mathrm{aq})$. Equally important, we expect that the newly accessible experimental information initiates theoretical calculations, particularly of the X-ray spectra from small metal-oxo oligomers in water.

\section{Conflicts of interest}

There are no conflicts to declare.

\section{Acknowledgements}

R. S., K. K., A. K., R. K., F. E., and B. W. gratefully acknowledge financial support from the Deutsche Forschungsgemeinschaft 
(DFG) within the Collaborative Research Center 1109 'Understanding of metal oxide/water systems at the molecular scale: structural evolution, interfaces, and dissolution'. R. S. gratefully acknowledges an Emmy Noether Young Investigator stipend through the DFG (project SE 2253/3-1). R. K. is thankful for financial support from the German Cluster of Excellence in Catalysis (UNICAT) funded by the German National Science Foundation (DFG) and managed by the Technical University of Berlin (TU Berlin). The authors thank the staff at the Helmholtz-Zentrum Berlin and BESSY II for assistance during the beamtimes. Open Access funding provided by the Max Planck Society.

\section{References}

1 R. M. Cornell and U. Schwertmann, The Iron Oxides - Structure, Properties, Reactions, Occurences and Uses, Weinheim, 2003.

2 J. F. Banfield, S. A. Welch, H. Zhang, T. T. Ebert and R. L. Penn, Science, 2000, 289(5480), 751-754.

3 T. Borch, R. Kretzschmar, A. Kappler, P. V. Cappellen, M. Ginder-Vogel, A. Voegelin and K. Campbell, Environ. Sci. Technol., 2010, 44(1), 15-23.

4 S. Dixit and J. G. Hering, Environ. Sci. Technol., 2003, 37(18), 4182-4189.

5 R. Chitrakar, S. Tezuka, A. Sonoda, K. Sakane, K. Ooi and T. Hirotsu, J. Colloid Interface Sci., 2006, 298(2), 602-608.

6 A. L. Rose and T. D. Waite, Environ. Sci. Technol., 2003, 37(17), 3897-3903.

7 A. Marcu, S. Pop, F. Dumitrache, M. Mocanu, C. M. Niculite, M. Gherghiceanu, C. P. Lungu, C. Fleaca, R. Ianchis, A. Barbut, C. Grigoriu and I. Morjan, Appl. Surf. Sci., 2013, 281, 60-65.

8 M. P. Sharrock and R. E. Bodnar, J. Appl. Phys., 1985, 57(8), 3919-3924.

9 R. Dronskowski, Adv. Funct. Mater., 2001, 11(1), 27-29.

10 E. Comini, V. Guidi, C. Frigeri, I. Riccò and G. Sberveglieri, Sens. Actuators, B, 2001, 77(1-2), 16-21.

11 G. Neri, A. Bonavita, S. Galvagno, P. Siciliano and S. Capone, Sens. Actuators, B, 2002, 82(1), 40-47.

12 P. Das, B. Mondal and K. Y. Mukherjee, $R S C A d v ., 2014$, (60), 31879.

13 A. Valdes, J. Brillet, M. Gratzel, H. Gudmundsdottir, H. A. Hansen, H. Jonsson, P. Klupfel, G.-J. Kroes, F. Le Formal, I. C. Man, R. S. Martins, J. K. Norskov, J. Rossmeisl, K. Sivula, A. Vojvodic and M. Zach, Phys. Chem. Chem. Phys., 2012, 14(1), 49-70.

14 P. Li, D. E. Miser, S. Rabiei, R. T. Yadav and M. R. Hajaligol, Appl. Catal., B, 2003, 43(2), 151-162.

15 J.-P. Jolivet, C. Chaneac and E. Tronc, Chem. Commun., 2004, (5), 481-483.

16 U. Schwertmann, J. Friedl and H. Stanjek, J. Colloid Interface Sci., 1999, 209(1), 215-223.

17 D. Gebauer, M. Kellermeier, J. D. Gale, L. Bergström and H. Cölfen, Chem. Soc. Rev., 2014, 43(7), 2348-2371.

18 H. Zhang, G. A. Waychunas and J. F. Banfield, J. Phys. Chem. B, 2015, 119(33), 10630-10642.
19 M. Zhu, C. Frandsen, A. F. Wallace, B. Legg, S. Khalid, H. Zhang, S. Mørup, J. F. Banfield and G. A. Waychunas, Geochim. Cosmochim. Acta, 2016, 172, 247-264.

20 J. Y. Bottero, A. Manceau, F. Villieras and D. Tchoubar, Langmuir, 1994, 10(1), 316-319.

21 D. Tchoubar, J. Y. Bottero, P. Quienne and M. Arnaud, Langmuir, 1991, 7(2), 398-402.

22 M. Zhu, B. Legg, H. Zhang, B. Gilbert, Y. Ren, J. F. Banfield and G. A. Waychunas, Environ. Sci. Technol., 2012, 46(15), 8140-8147.

23 J. Combes, A. Manceau and G. Calas, Geochim. Cosmochim. Acta, 1990, 54(4), 1083-1091.

24 J. M. Combes, A. Manceau, G. Calas and J. Y. Bottero, Geochim. Cosmochim. Acta, 1989, 53(3), 583-594.

25 C. M. Flynn, Chem. Rev., 1984, 84(1), 31-41.

26 W. Liu, B. Etschmann, J. Brugger, L. Spiccia, G. Foran and B. McInnes, Chem. Geol., 2006, 231(4), 326-349.

27 A. Stefánsson and T. M. Seward, Chem. Geol., 2008, 249(1), 227-235.

28 A. Kabelitz, A. Guilherme, M. Joester, U. Reinholz, M. Radtke, R. Bienert, K. Schulz, R. Schmack, R. Kraehnert and F. Emmerling, CrystEngComm, 2015, 17(44), 8463-8470.

29 J. Y. Bottero, D. Tchoubar, M. Arnaud and P. Quienne, Langmuir, 1991, 7(7), 1365-1369.

30 J. Combes, A. Manceau and G. Calas, Phys. Rev. B: Condens. Matter Mater. Phys., 1989, 158(1-3), 419-420.

31 R. N. Collins, K. M. Rosso, A. L. Rose, C. J. Glover and T. David Waite, Geochim. Cosmochim. Acta, 2016, 177, 150-169.

32 M. Zhu, B. W. Puls, C. Frandsen, J. D. Kubicki, H. Zhang and G. A. Waychunas, Inorg. Chem., 2013, 52(12), 6788-6797.

33 M. Zhu, Y. Wang, D. Meng, X. Qin and G. Diao, J. Phys. Chem. C, 2012, 116(30), 16276-16285.

34 J.-P. Jolivet, E. Tronc and C. Chanéac, C. R. Geosci., 2006, 338(6-7), 488-497.

35 J. Scheck, T. Lemke and D. Gebauer, Minerals, 2015, 5(4), 778-787.

36 J. Scheck, B. Wu, M. Drechsler, R. Rosenberg, A. E. S. Van Driessche, T. M. Stawski and D. Gebauer, J. Phys. Lett., 2016, 7(16), 3123-3130.

37 A. Manceau, Environ. Sci. Technol., 2012, 46(12), 6882-6884. 38 J. Dousma, T. Van den Hoven and P. L. De Bruyn, J. Inorg. Nucl. Chem., 1978, 40(6), 1089-1093.

39 A. Manceau and V. Drits, Clay Miner., 1993, 28, 165.

40 B. Lutz and H. Wendt, Berichte der Bunsengesellschaft für physikalische Chemie, 1970, 74(4), 372-380.

41 L. Spiccia, Inorg. Chim. Acta, 2004, 357(10), 2799-2817.

42 W. H. Casey, J. R. Rustad and L. Spiccia, Chem. - Eur. J., 2009, 15(18), 4496-4515.

43 R. Golnak, S. I. Bokarev, R. Seidel, J. Xiao, G. Grell, K. Atak, I. Unger, S. Thürmer, S. G. Aziz and O. Kühn, Sci. Rep., 2016, 6, 24659.

44 R. Seidel, S. Thürmer and B. Winter, J. Phys. Lett., 2011, 2(6), 633-641.

45 B. Winter and M. Faubel, Chem. Rev., 2006, 106(4), 1176-1211. 46 B. Winter, Nucl. Instrum. Methods Phys. Res., Sect. A, 2009, 601(1), 139-150. 
47 N. Kurahashi, S. Karashima, Y. Tang, T. Horio, B. Abulimiti, Y.-I. Suzuki, Y. Ogi, M. Oura and T. Suzuki, J. Chem. Phys., 2014, 140(17), 174506.

48 B. Winter, E. F. Aziz, U. Hergenhahn, M. Faubel and I. V. Hertel, J. Chem. Phys., 2007, 126(12), 124504.

49 S. Kline, J. Appl. Crystallogr., 2006, 39(6), 895-900.

50 S. Thürmer, R. Seidel, W. Eberhardt, S. E. Bradforth and B. Winter, J. Am. Chem. Soc., 2011, 133(32), 12528-12535.

51 R. Seidel, K. Atak, S. Thürmer, E. F. Aziz and B. Winter, J. Phys. Chem. B, 2015, 119(33), 10607-10615.

52 P. Wernet, D. Nordlund, U. Bergmann, M. Cavalleri, M. Odelius, H. Ogasawara, L.-Å. Näslund, T. Hirsch, L. Ojamäe and P. Glatzel, Science, 2004, 304(5673), 995-999.

53 S. Thürmer, R. Seidel, W. Eberhardt, S. E. Bradforth and B. Winter, J. Am. Chem. Soc., 2011, 133(32), 12528-12535.

54 B. Winter, R. Weber, W. Widdra, M. Dittmar, M. Faubel and I. Hertel, J. Phys. Chem. A, 2004, 108(14), 2625-2632.

55 B. Winter, R. Weber, I. V. Hertel, M. Faubel, P. Jungwirth, E. C. Brown and S. E. Bradforth, J. Am. Chem. Soc., 2005, 127(19), 7203-7214.

56 B. Winter, M. Faubel, I. V. Hertel, C. Pettenkofer, S. E. Bradforth, B. Jagoda-Cwiklik, L. Cwiklik and P. Jungwirth, J. Am. Chem. Soc., 2006, 128(12), 3864-3865.

57 R. Seidel, B. Winter and S. E. Bradforth, Annu. Rev. Phys. Chem., 2016, 67, 283-305.

58 A. P. Gaiduk, M. Govoni, R. Seidel, J. H. Skone, B. Winter and G. Galli, J. Am. Chem. Soc., 2016, 138(22), 6912-6915.

59 R. Seidel, S. Thürmer, J. Moens, P. Geerlings, J. Blumberger and B. Winter, J. Phys. Chem. B, 2011, 115(40), 11671-11677.
60 D. Yepes, R. Seidel, B. Winter, J. Blumberger and P. Jaque, J. Phys. Chem. B, 2014, 118(24), 6850-6863.

61 S. Thürmer, M. Ončák, N. Ottosson, R. Seidel, U. Hergenhahn, S. E. Bradforth, P. Slavíček and B. Winter, Nat. Chem., 2013, 5(7), 590-596.

62 I. Hjelte, M. Piancastelli, R. Fink, O. Björneholm, M. Bässler, R. Feifel, A. Giertz, H. Wang, K. Wiesner and A. Ausmees, Chem. Phys. Lett., 2001, 334(1), 151-158.

63 R. Golnak, J. Xiao, K. Atak, I. Unger, R. Seidel, B. Winter and E. F. Aziz, J. Phys. Chem. A, 2016, 120(18), 2808-2814.

64 S. Hüfner, Photoelectron Spectroscopy: Principles and Applications, Springer-Verlag, Berlin, Heidelberg, New York, London, Paris, Tokyo, Hong Kong, Barcelona, Budapest, 1995.

65 F. De Groot and A. Kotani, Core level spectroscopy of solids, CRC press, 2008.

66 H. Kanno and J. Hiraishi, J. Raman Spectrosc., 1982, 12(3), 224-227.

67 I. Pernoll, U. Maier, R. Janoschek and G. Zundel, J. Chem. Soc., Faraday Trans. 2, 1975, 71, 201-206.

68 R. Solbrig, L. Duff, D. Shriver and I. Klotz, J. Inorg. Biochem., 1982, 17(1), 69-74.

69 S. J. Oh, D. Cook and H. Townsend, Hyperfine Interact., 1998, 112(1-4), 59-66.

70 D. M. Carey and G. M. Korenowski, J. Chem. Phys., 1998, 108(7), 2669-2675.

71 A. K. Shiemke, T. M. Loehr and J. Sanders-Loehr, J. Am. Chem. Soc., 1984, 106(17), 4951-4956.

72 J. Seo, J. Jang, S. Warnke, S. Gewinner, W. Schöllkopf and G. von Helden, J. Am. Chem. Soc., 2016, 138(50), 16315-16321. 